\title{
La sutura de los mundos. Políticas del lenguaje en Rubén Darío
}

\author{
Daniel Link \\ Universidad de Buenos Aires / \\ Universidad Tres de Febrero
}

\section{Resumen}

La obra de Rubén Darío es un hito que vuelve a encontrar toda su fuerza en la discusión de los paradigmas hegemónicos en el campo de los estudios comparados, la Weltliteratur, el hispanismo y los estudios transatlánticos, no como caso para ser analizado sino como lugar de enunciación teórica que, como no podía ser de otra manera, anticipa algunos desarrollos de la teoría poscolonial y los estudios subalternos. Darío (como Caupolicán) no sólo soporta un mundo sobre sus espaldas, sino que interrumpe toda ilusión de homogeneidad y toda arrogancia en relación con algún centro. Nos dice que la lengua y el poema están en un lugar imposible y encuentra en esa imposibilidad un principio teórico, una ontología del presente y de nosotros mismos.

\section{Palabras clave}

· Rubén Darío · Weltliteratur · saberes subalternos · comparatismo - mundo

\footnotetext{
- Es catedrático y escritor. Dicta cursos de Literatura del Siglo XX en la Universidad de Buenos Aires y dirige la Maestría en Estudios Literarios Latinoamericanos en la Universidad de Tres de Febrero. Ha editado la obra de Rodolfo Walsh (El violento oficio de escribir, Ese hombre y otros papeles personales) y publicado, entre otros, los libros de ensayo La chancha con cadenas, Cómo se lee (traducido al portugués), Clases. Literatura y disidencia, Leyenda. Literatura argentina: cuatro cortes, y Fantasmas. Imaginación y sociedad, las novelas Los años noventa, La ansiedad, Montserrat $y$ La mafia rusa, las recopilaciones poéticas La clausura de febrero y otros poemas malos y Campo intelectual y otros poemas y su Teatro completo. Es miembro de la Associação Brasileira de Literatura Comparada (Abralic) y la Latin American Studies Association (LASA) y par consultor de CONEAU para la evaluación de programas de posgrado en el área de literatura comparada. Fue becario del CONICET y de la Fundación Guggenheim (2004). Ha dictado conferencias y cursos de posgrado en las universidades Humboldt (Berlín), NYU (USA), Penn (USA), Princeton (USA), Rosario, Tulane (USA) y UFSC (Brasil), Birkbeck College (Londres). En 2007 estrenó su primera obra de teatro, El amor en los tiempos del dengue y en 2011 publicó su primer libro para niños, Los artistas del bosque (Planta). Su obra ha sido parcialmente traducida al portugués, al inglés, al alemán, al francés y al italiano.
} 


\begin{abstract}
The work of Rubén Darío is a milestone that once again finds all its strength in the discussion of hegemonic paradigms in the field of Comparative Studies, the Weltliteratur, Hispanism and Transatlantic Studies, not as a case to be analyzed but as a place of theoretical enunciation that, as it could not be otherwise, anticipates some developments of postcolonial theory and subaltern studies.

Darío (as Caupolican) not only supports a world on his back, but interrupts every illusion of homogeneity and arrogance in relation to any center. He tells us that the language and the poem are in an impossible place and finds in that impossibility a theoretical principle, an ontology of the present and of ourselves.

\section{Key words}

- Ruben Darío - Weltliteratur · Subaltern Studies · Comparatism - World
\end{abstract}

Este artículo lleva como título La sutura de los mundos porque ése es el programa de interrogación en el que se inserta, cuyo objetivo es, a partir de Darío, un análisis de los procesos de globalización (económica) y mundialización (literaria) que produjeron el característico y horrísono sonido de la placas tectónicas que chocan entre sí exactamente cuando Rubén se puso a cantar, y su relación con lo que podemos llamar, muy en general, lo viviente.

Para quienes habitamos los territorios novomundanos, no hay mundo ni tiempo dados antes de Colón, de modo que el presente debería entenderse como un efecto de ese viaje que sella para siempre la doble cara de lo latinoamericano: lo «inviolable», lo que encanta a los sentidos, vs. lo «violado», lo integrado al orden de expansión capitalista. América es, luego de la sutura provocada por el intercambio colombino, un asunto del pensamiento y ese pensamiento estalla, en el Nuevo Mundo, alrededor del centenario de las independencias de las naciones hispanoamericanas, es decir en el cambio de siglo y, más precisamente, con la irrupción en la escena literaria de Rubén Darío, la primera figura planetaria, capaz de diseñar un pasado y un futuro americano desde una perspectiva mundial que ninguno de sus modelos franceses fue capaz de proponer.

La primera sutura de los mundos se produce en el registro de la vida desnuda: políticas de exterminio, trabajo forzado, animalización, desnudamiento. Papa, tomate, llamas, cuises y aborígenes son equivalentes (sobre todo, en el registro de la mercancía).

La segunda sutura es la de la vida cultivada, es decir, la vida de la polis, de las ciudades americanas, con sus culturas, sus procesos de mestizaje ya cumplidos, los procesos de integración operativa de lo disponible ya realizados, las sociedades ya 
fijadas e interpretadas como mímesis de las sociedades metropolitanas ${ }^{1}$, las políticas del lenguaje, de lo propio y de lo impropio.

Lo que Darío dice en ese contexto es que, porque somos muy pobres, debemos encarnizarnos en llegar a ser negros, indios, chinos, Caupolicanes o Eulalias y no en descubrir que lo somos, haciendo pueblo en la mal-dicción originaria (caribe, caníbal, Caliban). Y deducir, en ese encarnizamiento, una glotopolítica (diferente de la traducción como mera transposición idiomática) y una política literaria (diferente de la «importación» que los miopes le achacaron a Darío, que no importaba nada sino que era un portador, un infectado de vida cultivada), en suma: una superación del horizonte de la colonización. Darío no sólo desbarata el mapa literario mundial de su época sino que las operaciones que sostiene vuelven imposible incluso la idea de mapa, que habría que reemplazar por la de red (con sus nodos brillando intermitentemente).

El asunto quedará claro si se examinan tres ejemplos (que no se presentan cronológicamente porque están, en rigor, fuera-de-tiempo), tres operaciones de lenguaje típicamente darianas para dar cuenta de sus estrategias.

La primera de ellas es la intervención de 1892, cuando realiza su primer viaje transatlántico precisamente en ocasión de un centenario del viaje colombino. Darío llevó consigo un conjunto de piezas mayas y un texto en el que dignificó el arte amerindio, al que colocó en relación con las grandes tradiciones estéticas de Occidente, justo antes de que las vanguardias históricas comenzaran a volver al "primitivismo» (Einstein, 2008).

Lejos de toda celebración, $A$ Colón, el poema que lee ante los madrileños, es completamente crítico de la Conquista y pone al almirante como responsable de la decadencia americana. La conquista está concebida bajo la metáfora de la violación («Cuando en vientres de América cayó semilla/ de la raza de hierro que fue de España»). El poema textualiza a una de las primeras «imágenes de América» y una de las fenomenologías americanas más difundidas: la que luego Héctor Murena describirá en El pecado original de América (1954) como un proceso de mímesis europea nunca completo: "América ha sido interpretada según una clave puramente europea». Por eso mismo, "Todo el que quiere vivir tiene que matar, y sólo después del asesinato podrá reconciliarse con los muertos», dice.

La posición de Darío no es tan trágica pero es igualmente categórica, aunque sus categorías se levantan contra todo principio de autoridad y abren la lengua castellana hacia el tiempo del neologismo científico:

\author{
¡Desgraciado Almirante! Tu pobre América, \\ tu india virgen y hermosa de sangre cálida, \\ la perla de tus sueños, es una histérica \\ de convulsivos nervios y frente pálida. (Darío, 1953: 963-965)
}

A la fantasía pueril de los conquistadores y explotadores de los cuerpos, las palabras y las cosas como mercancías («la perla de tus sueńos»), Darío opone el nombre categorial «histérica» que Charcot, en el mismo momento en que el poeta escribe y recita, está codificando como trauma sexual en La Salpetrière (Las Leçons sur les maladies du système nerveux faites à la Salpêtrière se publicaron entre 1885 y 1887) y que terminará por convertirse en principio de la sexualidad femenina cuando Freud (discípulo de Charcot a partir de 1886) abrace la causa del fantasma. 
La primera operación, pues, enturbia la lengua introduciendo neologismos que cambian no sólo el paisaje del idioma sino, sobre todo, la relación de uso con los nombres y las categorías y que piensan el poema como instrumento de diagnóstico.

En el relato La muerte de la emperatriz de la China $(1890)^{2}$, Rubén Darío hace que el protagonista del relato, un escultor, oiga «un gran ruido de fracaso en el recinto de su taller» provocado por su mujer quien, por celos, rompe una estatuilla que el escultor atesoraba. La frase sólo se comprende del todo si se recuerda que fracas, en francés, significa estrépito y fracasser es romper con violencia. El fracaso dariano es un galicismo y la frase "ruido de fracaso», en este contexto, equivale a «Rey de Reyes», que se suma a los sentidos más obvios, pero sin cancelarlos del todo: ruido de rotura y violento fracaso de la idolatría (callejón sin salida de las religiones, pero también de las políticas) ${ }^{3}$. $\mathrm{El}$ «fracaso» dariano se instala en el medio de los desgarros que produce la globalización, a la que interrumpe (interrumpere: romper algo y poner un espacio entre los pedazos).

En esta segunda operación se deja leer una política de la traducción, si se quiere, pero también, y sobre todo, una política de las lenguas en contacto. Expulsado de los listados académicos como "galicismo», el «fracaso» de Darío destruye toda ilusión de pureza y homogeneidad lingüística: el castellano, a diferencia de cualquiera de las otras lenguas romances estatales, es una totalidad quebrada e imposible de ser recuperada como tal y esto no sólo por la declinación territorial de los sistemas pronominales, los léxicos y los ritmos sintácticos, sino sobre todo porque la lengua americana, despojada de todo fundamento, se revela como un mero espacio de transfiguración, zona de contacto y de fricción, principio de desidentificación ${ }^{4}$.

Un atento lector de la obra dariana ha observado que «como traductor, Darío es un caníbal exquisito» (Caresani, 2012). Entiéndase la afirmación en todo su alcance: en relación con la figura calibanesca sobre la que el propio Darío reflexiona (y la maldicción que la funda), a la par que algunos de sus coetáneos (no digo contemporáneos porque la relación de contemporaneidad es otra cosa: Darío es nuestro contemporáneo, Rodó no lo es tanto), pero en relación, sobre todo, con el canibalismo cultivado propuesto por la vanguardia paulista como clave de la situación latinoamericana (incluso, si se quiere, en relación con la antropología posestructural de Viveiros de Castro) ${ }^{5}$.

El carácter siempre presente de la traducción en el corpus dariano ha sido particularmente analizado en relación con el primer poema de Prosas Profanas (publicado en Buenos Aires en 1896), "Sinfonía en gris mayor», que "traduce», como se sabe, la Sinfonía en blanco mayor (1849) de Théophile Gautier, y el Arte poética (1874) de Paul Verlaine, pero también un género pictórico (la marina) y un paisaje (el trópico) a un poema que es una intervención en el Buenos Aires al que Darío acaba de llegar (un ambiente tensionado entre el criollismo, el hispanismo y el cosmopolitismo). Sea: el traductor, como se ha dicho, como antropófago y la antropofagia como una antropología.

Me detengo en la penúltima estrofa para ejemplificar la tercera operación dariana que trataré luego de traer a nuestro presente y nuestras preocupaciones:

La siesta del trópico. El lobo se aduerme.

Ya todo lo envuelve la gama del gris.

Parece que un suave y enorme esfumino

del curvo horizonte borrara el confin. 
Por un lado, se borra el confín, que es tanto «el último término a que alcanza la vista» como el "término o raya que divide las poblaciones, provincias, territorios, etc., y señala los límites de cada uno». Se trata de una apertura y de una amplificación: la suspensión de todo veredicto retrógrado en relación con los lenguajes, los imperios y las naciones, una interrogación de los gestos (en suma: las formas y las imágenes de las que disponemos) no como si fueran interiores a la literatura, al arte, a la cultura sino como siendo exteriores a toda garantía cultural y disciplinar, participando de una exterioridad radical (lo abierto rilkeano o el afuera blanchotiano: Heidegger, 1996 y Foucault, 1966). Pero no es esto lo que ahora importa.

La primera edición del poema, publicado en el periódico El Correo de la Tarde (Guatemala) el 21 de febrero de 1891 dice «duerme». El 3 de mayo de 1891 se republica en La Habana Elegante (Cuba) con una única variante: la transformación de «duerme» en «aduerme», que es la que llega hasta nosotros. La corrección de Darío, que sostiene las mismas cantidades silábicas del verso produce, sin embargo, una elongación rítmica que busca hacer coincidir el ritmo con la ensońación o el sueño opiáceo ${ }^{6}$ del lobo de mar, el marino que protagoniza el poema. El hallazgo es extraordinario porque permite establecer una relación de semejanza y contigüidad entre el verso y el proceso que representa, y para hacerlo el poema recurre a una palabra caída en desuso, infrecuente, como se buscan los tesoros en una mina o una excavación 7 .

De modo que la glotopolítica dariana reposa en unas estrategias que llevan la lengua a un lugar en donde nunca está: su propio pasado (aduerme), su propio futuro (histeria) y las lenguas de allende el confín (fracaso). La lengua de Darío (la lengua americana) jamás podrá coincidir con la lengua española ni con sus fantasías extraccionistas (la lengua como recurso natural a ser explotado: RAE, Telefónica, grupo Prisa, Santillana) ni tampoco puede coincidir consigo misma porque es una lengua que funciona como línea de fuga (hacia el pasado, hacia el futuro, hacia afuera).

Hay que detenerse en estos pormenores porque se los puede poner en correlación con algunas tensiones teóricas de nuestro tiempo y nuestro espacio, milenarismo y globalización que, cada una a su manera, acaban con toda ilusión de autonomía de los fenómenos estéticos (Ludmer, 2010). Esta singularidad ejemplar permite desplegar las perplejidades que forman parte del comparatismo, puesto bajo la interrogación de la dialéctica entre centro y periferia, el cuestionamiento del eurocentrismo o la heteronomía de los asuntos artísticos y culturales, las negociaciones, tensiones y dislocamientos del valor estético en la producción contemporánea y, naturalmente, nociones como «literatura mundial» $\mathrm{o}$ «sur global», que participan, al mismo tiempo, de lo estético y de lo ético.

Darío como caso del comparatismo participa tanto de los juegos de lenguaje transnacionales y la crisis de los universales burgueses como de la tangencial alusión a la vida literaria y la guerra de discursos, un caso que involucra tanto el anacronismo y la catástrofe, o la noción de comunidad entendida no como el paraíso de las semejanzas sino como el infierno de las diferencias.

En efecto, ¿a qué otra cosa podría aludir hoy la Weltliteratur sino a un mundo interrumpido (despedazado), tal y como se deduce de Histoire(s) du cinema de Godard, que en una de sus más admirables secuencias opone al "totalitarismo del presente» (en la voz de Godard), la cita de Paul Celan («si un hombre... viniese...», «Kämme ein Mensch») y, resonando en ella, el enmudecimiento radical de Hölderlin? 
Si para nosotros, hijos de Metapa, hay mundo y Weltliteratur es porque las estrategias darianas destruyeron toda ilusión de totalidad lingüístico-literaria-cultural. ¿Se puede pensar lo literario como figura del mundo una vez que el lenguaje que constituye su materia ha sido desidentificado de sí mismo? Para hacerlo, habría que poner en crisis los grandes modelos del comparatismo actual.

Ignacio Sánchez Prado ha censurado los modelos hegemónicos de «la literatura mundial tal como la plantean Moretti y Casanova», por ejemplo, porque en ellos se definen "agendas que corresponden estrictamente a intereses intelectuales euronorteamericanos» y donde "Latinoamérica sigue siendo el lugar de producción de "casos de estudio", pero no un locus legítimo de enunciación teórica» (Sánchez Prado, 2006: 9).

Ese locus es el que reivindicaba Darío, quien entendió la situación de lo latinoamericano como un horizonte de tensiones entre dos yacimientos de pasado (Europa y América) y reprogramó, en relación con esas tensiones, la memoria colectiva de América, que debe tanto a los centauros parlanchines como a Tutecotzimí («Mi piqueta/ trabaja en el terreno de la América ignota»). Que no se trata solamente de un programa estético lo demuestran las intervenciones de Darío en las Conferencias Panamericanas (especialmente en la Conferencia Panamericana de Río de Janeiro, que tendrá particular resonancia en su obra).

Pero las estrategias darianas sirven también como alerta contra los peligros de otra operación: la transformación del hispanismo en «estudios transatlánticos». En un artículo irreprochable en sus argumentos, Eduardo Subirats enuncia «siete tesis contra el hispanismo»: los «dilemas aduaneros» que suscita, el prejuicio esencialista y concentracionario de la lengua única, el carácter quebrado y colonizado de la modernidad ibérica, entre otros aspectos (Subirats, 2004: 149-166).

Por su parte, en abierta oposición a Julio Ortega, Abril Trigo censuró la mutación del hispanismo en estudios transatlánticos porque «la exaltación de la uniformidad lingüística del español y su meticulosa explotación como recurso económico está en la base de una muy bien planeada estrategia geopolítica» (Trigo, 2012: 35), que procura restablecer la hegemonía moral y cultural de la antigua metrópolis sobre el mundo de habla hispana ${ }^{8}$.

Entre otros aspectos, Trigo se detiene sobre todo en la «estratagema» anti-teórica de los estudios transatlánticos (Trigo, 2012: 24):

una ingeniosa estratagema cuyo fin es establecer una muy peculiar posición estratégica, el punto de vista privilegiado de quienes no se oponen a la teoría, sino que la superan, desde que han logrado salir relativamente ilesos de las batallas académicas e institucionales de los noventa, situación que les permite abrogarse la autoridad moral e intelectual para hacer borrón y cuenta nueva. Esto implica, por supuesto, la adopción de un nuevo paradigma crítico y teórico: los estudios transatlánticos, que gracias a su postura post-teórica no pueden ser nombrados ni teorizados como tal. La estratagema post-teórica hace posible pasar lo que es una práctica hermenéutica como un nuevo paradigma teórico, evitando asi que se vea sometida al escrutinio de la crítica.

O, para decirlo con palabras de Josefina Ludmer, que sitúa la aparición de un nuevo tipo de literaturas, las «literaturas postautónomas» en el horizonte de una crisis de las políticas representativas tradicionales, de los sistemas políticos y los estados: 
Las literaturas postautónomas (...) se regirian por otra episteme. Y lo que contarian en la imaginación pública sería una pura experiencia verbal [de la lengua: la lengua se hace en ellas recurso natural e industria] subjetiva-pública de la realidad-ficción del presente en una isla urbana latinoamericana (Ludmer, 2010: 183).

Lo que antes propuse como red, podría llamarse, siguiendo estas indicaciones, archipiélago, con la condición de no proyectar lo insular de la definición sobre un mapa plano sino en el diagrama de una constelación (donde las distancias no son homogéneas).

Vuelvo al fracaso dariano, que ahora podríamos interpretar no como un capricho poético sino como una herramienta político-cognitiva, en la línea de un Simón Rodríguez leído por León Rozichner («Entonces se impone la pedagogía: hay que enseñar y aprender desde el fracaso", Rozitchner, 2012: 47) hasta Gayatri Spivak, para quien el fracaso constituye un método.

La perspectiva dariana, en efecto, parece coincidir con la de la más conocida cultora de los Estudios Subalternos de la Escuela India, que fueron introducidos en América latina en 1998 por la socióloga aymará Silvia Rivera Cusicanqui (Gago, 2016), junto con Rossana Barragán (1998), mucho antes de que se convirtieran en moda académica. La antología traducida quería contestar al multiculturalismo neoliberal que se imponía como política estatal en el mismo sentido en que funciona el perspectivismo antropológico de Viveiros de Castro.

Los estudios poscoloniales que allí se presentaron tenían por objeto «restituir a los (grupos, clases) subalternos su condición de sujetos plurales y descentrados, que habitan de un modo territorial la espesura histórica» (Barragán 1998: 11). La «sociedad civil abigarrada — la sociedad subalterna - (...) siempre permanece heterogénea y elusiva a la política de los de «arriba»» (op.cit), pero también a las conceptualizaciones del marxismo ilustrado (de José Carlos Mariátegui a Ángel Rama).

La subalternidad como herramienta teórica no tuvo demasiado éxito en el contexto de los estudios gramscianos (que fue el primero en proponerla) sino hasta hace muy poco: la subalternidad, los lenguajes y los saberes subalternos. Gramsci despreciaba un poco la desagregación y la discontinuidad de los grupos caracterizados como subalternos, «siempre sujetos a la iniciativa de los grupos que gobiernan, incluso cuando se rebelan y sublevan».

Hubo que esperar hasta los Cultural Studies de matriz inglesa, en primer término, y luego hasta los Subaltern studies (Ranajit Guha, Gyan Pandey, Shahid Amin, Partha Chatterjee, Dipesh Chakrabarty, entre otros), que promovieron un examen sistemático de los temas subalternos en el campo de estudios sudasiáticos, para que los saberes subalternos adquirieran una dignidad analítica semejante a la de los saberes hegemónicos. En esa línea, Gayatri Spivak ha explicado «la resistencia económica actual de las mujeres subalternas» como «lo local enfrentándose a lo global, el saber diversificado enfrentándose a la monocultura» (Spivak, 2010: 111).

En América Latina, si bien la noción aparece en abordajes como los de Aziz Nassif, Rhina Roux o Melgar Bao, es notable la desatención a la subalternidad en los estudios de José Aricó, Juan Carlos Portantiero, Carlos Coutinho e incluso Ernesto Laclau, en favor de otras nociones como hegemonia, bloque histórico e intelectual orgánico. En 1992, debido al rápido auge que alcanzaron los Subaltern studies en los Estados Unidos, se formó el Grupo de Estudios Subalternos Latinoamericanos, integrado por John Beverley, Walter Mignolo, Javier Sanjinés, Patricia Seed, Ileana 
Rodríguez y otros, quienes reaccionaron contra el reduccionismo burocrático en el que habían caído los Estudios Culturales Latinoamericanos, inscriptos en una racionalidad académica imperial y totalizante.

El más cercano a la literatura de esos críticos culturales, Walter Mignolo, ha tratado últimamente de relacionar el pensamiento poscolonial o los procesos de descolonización del pensamiento con ciertas tradiciones subalternas, legibles en textos que van desde Guaman Poma de Ayala hasta Frantz Fanon.

Por otro lado, en consonancia con las hipótesis de Boaventura de Sousa, Silviano Santiago ha acuñado los términos «entre-lugar del discurso latinoamericano» y «cosmopolitismo del pobre» (Santiago, 2014) ${ }^{\text {. }}$.

En cualquiera de estas perspectivas, el subalterno como sujeto, y los lenguajes y saberes que sostiene y desempeña, cuestiona la caracterización de pre o sub-político que pareciera deducirse del cuerpo gramsciano (Galindo, 2005).

La relación Sur-Sur, entonces, se verifica en la estratégica traducción de un triste trópico (el indio) a otro (el del altiplano boliviano), ninguno de los cuales puede considerarse una versión temporal ${ }^{10}$ de Europa y sus "palacios de las universidades del norte». Cuando Gayatri Spivak visitó Bolivia, Silvia Rivera Cusicanqui le propuso traducir el término double bind, de gran fortuna en la teoría social (de Bateson a la propia Spivak pasando, naturalmente, por Deleuze) con el término aymara pä chuyma, que significa «tener el alma dividida por dos mandatos imposibles de cumplir» (Gago, s/f).

El castellano, esa lengua interrumpida por la errancia desde las estrategias fundadoras de Rubén Darío, carece de una palabra para traducir con precisión un concepto que el aymara sí conoce. Una vez más, El coloquio de los centauros bien puede traducirse como Tutecotzimí.

Y, sobre todo, hay que subrayarlo nuevamente, el desequilibrio de un lenguaje sin totalización posible (porque no tiene presente ni confín, sino sólo pasado, futuro y afuera), teniendo en cuenta el carácter perspectivista propio de los estudios poscoloniales, permite entender mejor todavía la abundancia de chinoiserie en la obra dariana porque «el desplazamiento de los centros es un hecho, dice Silvia [Rivera Cusicanqui] (que además, insiste con que si nombramos desde donde estamos situadxs, ¡el oriente refiere a Europa!)»(Gago, 2016, nota 20).

La teoría social que tal vez sirva de insumo para un nuevo diagrama de la literatura mundial parece haber llegado a un lugar eminentemente dariano. Habrá que perdonarle su retraso. 


\section{Notas}

${ }^{1}$ Marx siguió «las palabras de su maestro Hegel, quien en sus Lecciones sobre la filosofía de la historia universal afirmaba que cuanto acontecía en el Nuevo Mundo no era sino el eco del Viejo mundo y, por tanto, el reflejo de una vida ajena. América debía aún separarse del suelo sobre el cual se había desarrollado hasta ese momento la historia universal, pero esto era únicamente una probabilidad cuyas condiciones de realización todavía no podían ser previstas (Aricó, 2009: 139). Simón Rodríguez, el maestro de Bolívar, sufría contemporáneamente porque «Vemos a los europeos inventando medios de reparar un edificio viejo, por no tener dónde hacer uno nuevo; vemos a los americanos, en un país vacío, perplejos, o imitando sin necesidad lo que hacen los Europeos (...) la América no debe imitar servilmente sino ser original». Citado por Rozitchner, 2012: 146-147.

${ }^{2}$ En el prólogo a Darío, 1995, José María Martínez precisa: «El cuento se publicó por primera vez en La República (Santiago, 15 de marzo de 1890), con la misma dedicatoria que luego se reprodujo en [la segunda edición del] 90 [Alduque Job \{i. e.: Manuel Gutiérrez Nájera\}, de México]. El 15 de mayo de ese mismo año se insertó en las páginas de La Unión [San Salvador, a mi entender]. En junio pudo leerse además en El Perú Ilustrado de Lima (día 5), con una presentación de Ricardo Palma, y en El Imparcial de Guatemala (día 15), donde aparece firmado por Darío». ${ }^{3}$ Según Ottorino Pianigiani, en fracassare (que pasa a las demás lenguas romances), el prefijo italiano fra reemplaza al con de conquassare (el resultado equivale al interrumpere y significaría, por lo tanto «en medio de la sacudida»). El diccionario está disponible en https://www.etimo.it/ ${ }^{4}$ De otras lenguas coloniales americanas como el inglés y el portugués de América podría decirse lo mismo (Brasil y Estados Unidos aprobaron sendas reformas ortográficas) pero el caso del castellano (o su identificación con la lengua imperial bajo el rótulo español) es distinto, como se verá más adelante.

${ }^{5}$ Cfr. Darío, 1998 y 1896. También Fernández Retamar, 1989 y, especialmente, Viveiros de Castro, 2010.

${ }^{6}$ Se podría pensar en el «onirismo tóxico» que tanto le interesaba a Darío, pero eso aquí no importa. La primera aparición del vocablo está registrada en el Vocabulario de las dos lenguas, Toscana y Castellana (Cristóbal de las Casas, 1570) donde la palabra, en efecto, se relaciona con la «adormidera»: adormecido: addormentato; adormir: allopiare; adormideras: papaueris; etc. Agradezco estas referencias a Rodrigo Caresani (comunicación personal).

7 «Pocos se preocupan de la forma artística, del refinamiento; pocos dan - para producir la chispa - con el acero del estilo en esa piedra de la vieja lengua, enterrada en el tesoro escondido de los clásicos» (Darío, 1934: 171).

${ }^{8}$ Prueba de lo cual sería el discurso de Lázaro Carreter, presidente de la Real Academia Espańola, en el Congreso de Sevilla: «la presencia 
hispánica, actual y futura, en el concierto o desconcierto del mundo, depende decididamente de la unidad idiomática (...) la Real Academia siente que ha llegado el momento de intensificar sus actividades en pro de esta causa que dista de ser estética, y llega a ser decididamente política» (Instituto Cervantes, Sevilla, 1992)

${ }^{9}$ Boaventura usa la noción de "cosmopolitanismo subalterno" para referirse a prácticas contra-hegemónicas y luchas globales

${ }^{10}$ Es la soprendente perspectiva de Claude Lévy-Strauss en Tristes trópicos: América es el pasado de Europa; la India, su futuro.

\section{Referencias bibliográficas}

Aricó, J. (2009). Marx y América Latina. Buenos Aires: FCE

Barragán, R. (1998). Debates Post Coloniales. Una introducción a los Estudios de la Subalternidad. La Paz: Historia-Sephis-Aruwiyiri

Caresani, R. (2012, mayo). Rubén Dario traductor: poesia, pintura y música. Ponencia presentada en VIII Congreso Internacional Orbis Tertius: Literaturas Compartidas organizado por Universidad Nacional de la Plata. Buenos Aires

DARío, R. (1896). Los raros. Buenos Aires/ Barcelona: Maucci (edición original 1905).

(1934). Obras desconocidas de Rubén Dario, edición de Raúl Castro Silva. Santiago de Chile: Prensas de la Universidad de Chile. (1953). Obras completas. Tomo V. Madrid: Afrodisio Aguado. (1995). Azul... / Cantos de vida y esperanza. Madrid: Cátedra. (1998). «El triunfo de Caliban», El tiempo (Buenos Aires: 20 de mayo de 1898), republicado con notas de Carlos Jáuregui en Revista Iberoamericana, 184-185. Pittsburgh: 1998

EInSTEIn, C. (2008). El arte como revuelta. Escritos sobre las vanguardias (1912-1933). Madrid: Genérico

Fernández Retamar, R. (1989). Calibán and Other Essays. Minneapolis: University of Minnesota Press.

Foucault, M. (1999). El pensamiento del afuera (traducción Miguel Morey). En Obras esenciales I: Entre filosofía y literatura. Buenos Aires: Paidós (edición original 1966).

Gago, V. (2016, noviembre). Saberes subalternos de América Latina: pequeño mapa de polémicas y desacuerdos. Conferencia de cierre en VII Jornadas de Jóvenes Investigadores en Estudios Comparados Arte, literatura, lenguaje, género: "Saberes subalternos de América Latina». Buenos Aires. (s/f). Contra el colonialismo interno. Anfibia. Recuperado de: http://www.revistaanfibia.com/ensayo/contra-el-colonialismointerno/\#sthash.lyEd5wef.dpuf

Galindo, G. (2005). Los Estudios Subalternos, una teoría a contrapelo de la Historia. Revista Humanas, 2.

Heidegger, M. (1996). ¿Para qué poetas? (trad. Helena Cortés y Arturo Leyte). En Caminos del bosque. Madrid: Alianza. 
Ludmer, J. (2010). Aqui América Latina. Una especulación. Buenos Aires: Eterna Cadencia

Rozitchner, L. (2012). Filosofía y emancipación. Simón Rodríguez: el triunfo de un fracaso ejemplar. Buenos Aires: Biblioteca Nacional.

Sánchez Prado, I. (2006). «Hijos de Metapa»: un recorrido conceptual de la literatura mundial (a manera de introducción). En Sánchez-Prado, I. (editor) América Latina en la literatura mundial. EE.UU.: Biblioteca de América, Universidad de Pittsburgh.

Santiago, S. (2014). A literatura brasileira à luz do pós-colonialismo. Folha de São Paulo (San Pablo: domingo 7 de septiembre). Recuperado de http://www1.folha.uol.com.br/ilustrissima/2014/09/1511606aliter aturabrasileiraaluzdoposcolonialismo.shtml

SpIVAK, G. (2010). Crítica de la razón poscolonial. Madrid: Akal Subirats, E. (2004). Siete tesis contra el hispanismo. Revista de Humanidades: Tecnológico de Monterrey, 17.

Trigo, A. (2012). Los estudios transatlánticos y la geopolítica del neo-hispanismo. Cuadernos de Literatura de la Pontificia Universidad Javeriana, 31 (enero-junio). Bogotá.

Viveiros De Castro, E. (2010). Metafísicas caníbales. Buenos Aires: Katz.

\section{Link, Daniel}

«La sutura de los mundos. Políticas del lenguaje en Rubén Darío». El hilo de la fábula. Revista anual del Centro de Estudios Comparados (18), 13-23. 